\title{
The Faculty of Homeopathy: Celebrating 175 Years of Excellence in Homeopathic Practice
}

\author{
Gary J. Smyth ${ }^{1}$ \\ 1 President, Faculty of Homeopathy, London, United Kingdom \\ Homeopathy 2019;108:223-229.
}

\section{Early Beginnings in London}

On 10th April 1844, the inaugural meeting took place of what was then called the 'British Homoeopathic Society' (BHS). This meeting was held in the residence of Dr Frederick Hervey Foster Quin in Arlington Street, Piccadilly, London, with several notable doctors in attendance, including Dr Constantine Hering, who was on a visit to the United Kingdom at the time. The date chosen was the birthday of Dr Samuel Hahnemann-the first one that followed his death the previous year on 2nd July 1843. Dr Quin took the position of first President of the organisation, a role in which he continued until his death in 1878.

The BHS continued for 100 years and was renamed as 'The Faculty of Homeopathy' in 1944. The organisation was incorporated by an Act of the UK Parliament in 1950. Since its founding, there have been 175 years of homeopathic practice, many well-known personalities, some high points and low points, and many patients whose lives have been turned around as a result of homeopathic treatment.

The formation of the BHS/Faculty laid the groundwork for the establishment of the UK's homeopathic hospitals shortly afterwards. The London Homoeopathic Hospital was established in Golden Square, Soho, in 1849, moving to its present location in Great Ormond Street in 1859. By permission of King George VI, the hospital became known as the Royal London Homoeopathic Hospital (RLHH) in 1947. Although the hospital and the BHS/Faculty have always been separate institutions, their history has been closely intertwined. The work of Quin and the establishment of the BHS/Faculty was the foundation upon which the entire UK homeopathic tradition developed and subsequently spread to many other parts of the world.

\section{Developments in the United States of America}

Such was the impact of Hahnemann's death upon his followers, colleagues and patients, that whilst Dr Quin was holding the inaugural meeting of the BHS in the UK a similar meeting was taking place in America. At this meeting, the American Institute of Homeopathy (AIH) was founded, thus making the Faculty of Homeopathy and the AIH two of the longest established homeopathy organisations in the world. This special 175th anniversary year has seen a variety of events to mark these two important milestones in our shared history. In this issue, I am delighted to welcome a Guest Editorial from my colleague $\mathrm{Dr}$ Susanne Saltzman from New York, President Elect of the AIH. ${ }^{1}$

\section{Echoes from the Past}

With 175 years of rich history, this editorial is not the place for a detailed account of all the characters, events and publications that have contributed to the establishment of homeopathic practice as we know it today. One could easily fill an entire volume with fascinating details and worthy contributions from the giants who have gone before us. Indeed, several detailed works have been produced on the history of British homeopathy. ${ }^{2-4}$ However, such a thesis has yet to be written specifically on the history of the Faculty of Homeopathy, and I trust that some colleagues will do this in future-whether practitioner, historian or researcher.

Nevertheless, given the occasion of our quartoseptennial anniversary, it is important to glance over the years that have gone by and briefly highlight some of the significant moments and milestones of our collective history. I trust that readers will forgive me for the inevitable omissions and
Copyright $\odot 2019$ The Faculty of Homeopathy
DOI https://doi.org/ 10.1055/s-0039-1700534. ISSN $1475-4916$. 
the necessary brevity of my comments. This is in no way a reflection on their importance, but rather a consequence of the limited space within this editorial.

In the 175 years since that inaugural meeting in London, there have been many thousands of doctors and other healthcare professionals who have been members of the Faculty of Homeopathy. Many of them, through their hard work and dedication, have etched their names into our history and are remembered forever for their contributions. To date, there have been 81 Presidents of the Faculty, 98 Faculty-organised Congresses, and 108 years of publication of this journal, which has been edited by no fewer than 17 esteemed colleagues, ${ }^{5}$ including the current Acting Editor.

\section{Homeopathy Journal}

In the early years following the foundation in 1844, there were various other organisations, reflecting the various schools of thought and divergence of opinion that existed at the time. There were also several notable publications in those early days, including the Journal of the British Homoeopathic Society, The Annals and Transactions of the British Homeopathic Society, The British Homoeopathic Review, The Annals of the London Homoeopathic Hospital, the British Journal of Homoeopathy and various others. These publications are available in various locations and contain a wealth of fascinating material regarding those early years.

In January 1911, this current journal was launched as the British Homoeopathic Journal, with the first Editors being Dr Giles Forward Goldsborough and Dr Thomas George Stonham, both of whom were former Presidents of the BHS. In their opening editorial note, they stated 'The aim of this Journal is not dogmatism but an exhibition of practical experience illustrating the rule of Similars'. ${ }^{5}$ The journal continued with slight modifications of the spelling of the name and then, in 2001, the name was changed to its current, Homeopathy. One of the reasons for the change of name was to reflect the increasingly international nature of the publication.

From 1998, the journal has been published in partnership with a commercial publisher. This was initially Stockton Press, then Elsevier from 2002, and Thieme Medical Publishers from 2018 to the present. An historic milestone was achieved in 1998 when the journal was accepted for indexing in Medline. In 2009, the journal received an Impact Factor, which has continued to show a healthy improvement since then. These changes have resulted in an increase in the journal's status, and now in 2019, Homeopathy has become the leading international journal for homeopathy research, with over 100,000 downloads per year. It continues to occupy a unique and special place as being the only peer-reviewed journal dedicated to homeopathy, indexed in Medline and with an Impact Factor.

The longest serving Editor of the journal was Dr Peter Fisher, the incumbent for 32 years from 1986 to 2018. It was under his editorship that peer review was introduced, Medline listing was achieved, an Impact Factor was awarded and a definite change was made to transform what was a British-focused publication into a truly international journal of homeopathy. Nowadays, one only has to glance at the first few pages of a volume to see the international flavour of both the Editorial Board and the origin of the published papers. In this edition, for example, I am glad to see review or original research articles from authors in Brazil, India, Israel, Turkey and the Netherlands.

In 2011, the journal celebrated its centenary, with a fascinating selection of reprinted papers from each decade of its history. I would encourage readers to revisit some of those papers, plus the accompanying editorial by Dr Peter Fisher in which he speculated on what the future might hold. ${ }^{5}$ The same issue also features an interesting reflective article by $\mathrm{Dr}$ Anthony Campbell, who edited the journal from 1981 to $1986 .{ }^{6}$

\section{Leading Lights, 1844-1944}

Aside from Dr Quin's, there are many names of other wellknown members from the early years of the organisation, some of whom also occupied the position of President. Amongst others, these include Dr Robert Ellis Dudgeon, Dr Alfred Crosby Pope, Dr John Galley Blackley and Dr John Henry Clarke. John Blackley's father was Dr Charles Harrison Blackley, a physician at the Manchester Homoeopathic Hospital, who contributed greatly to our understanding of immunology and, in particular, hay fever. Through his research, he was the first person to identify pollens as the cause of hay fever, ${ }^{7}$ and the first person to fully describe and study allergens. ${ }^{8}$ In 1873 , he was so impressed by the infinitesimal quantity of allergens required to cause the symptoms of hay fever that he trained in homeopathy. ${ }^{9}$

Dr Richard Hughes deserves special mention, being known as the 'Grand Old Man of British Homeopathy'. He was a prolific writer and scholar and was appointed as Lecturer in Materia Medica by the BHS. He was famously a low-potency prescriber, who advocated a pathological approach and emphasised the need to maintain a scientific basis to homeopathy. He also encouraged a close relationship between homeopathic and allopathic physicians, pursuing a much more integrated approach than had been the case previously. Needless to say, this generated considerable opposition within the homeopathy community and elsewhere.

One of Richard Hughes' most significant publications was the four volumes of his Cyclopaedia of Drug Pathogenesy, which took 7 years to prepare (1884-1891) and which was a joint project between the BHS and the AIH. ${ }^{10}$ In 1898, Richard Hughes was present when Samuel Hahnemann's body was disinterred from his tomb for reburial under a more suitable memorial at the Père Lachaise Cemetery in Paris. ${ }^{11}$ Such was his impact on homeopathy, the Faculty of Homeopathy still organises an annual 'Richard Hughes Memorial Lecture' in London.

In 1894, the organisation marked the 50th anniversary of its founding. The President at the time was Dr Hugh Cameron, who was the only person then still alive that had been present at the inaugural meeting 50 years earlier. In his introductory address, he included his first-hand recollection of the occasion:

'In the name of the British Homoeopathic Society, and in my own, I do heartily bid you welcome and congratulate you on this the joyful occasion of the first meeting of the Jubilee 
Session of our beloved Society. It is impossible for me to express my gratification in having the privilege of taking a part in this celebration, and in witnessing the full realization of those sanguine hopes (not unmixed with anxieties and fears), which animated that little band of devoted men, only eight in number, who, fifty years ago, rallied round Dr Quin on that night when he laid the first stone of the foundation of this Society, and of whom I alone survive. When I think of that scene, that round baize-covered table we all sat at, with room to spare, of the faces of so many friends - Quin, Partridge, Giglioli, Mayne, Dunsford, Hering, Wood (whose features and expressions and manners are as clearly in my recollection at this moment as if I had seen them only yesterday), notwithstanding the cordial satisfaction which I experience at present in beholding the splendid proportions of this gathering, and then recall to memory that little circle half a century ago, the retrospect, I assure you, is one of no small sadness to me. Our present most prosperous condition could not be more enthusiastically hailed by us than by those first members, could they have witnessed it. In one glorious respect our Society, however large its proportions and however general the influence of homeopathy may become, can never surpass that lofty spirit of honour that permeated the whole of that little band - a spirit that in all ages, and in the noblest traditions of our great profession, has ruled the conduct of all medical men worthy of the name. May that vital spirit be the guide of every colleague whom the Society admits to its ranks! Success may not always attend even our most worthy members, but honourable conduct is within the possession of us all; no success can ever be a recompense which is won by the sacrifice of honour. ${ }^{12}$

Another worthy mention from this period is Dr Fewster Robert Horner, an ardent opponent of homeopathy, who was closely involved in suppressing the cholera statistics of the London Homoeopathic Hospital in 1854. He was also a former President and Vice President of the British Medical Association. However, after being tasked with investigating homeopathy, he realised its potential and later became a homeopathic physician. In 1868, he wrote: 'Yet up to the very time of instituting my enquiry - and it is with humility I make the confession - blinded by prejudice and ignorance, like most of the profession in Hull and elsewhere, I deemed Homeopathy a vain and impossible thing. [...] I had far more expectation of unmasking and exposing it as a fallacy, than I had of finding in it that good by which the evils of the old practice of medicine might be obviated, and a more gentle but a far more efficient method of cure be substituted. [...] I felt that the time had arrived when something must be done, both by the individual and the collective efforts of the profession: the onward spread of Homeopathy must be stayed. [...] Notwithstanding the oft repeated declaration of my professional brethren to the contrary, it was too apparent that it was not 'dying out', but was steadily progressing, nay, rapidly extending itself. [...] Strange, strange, truly, that the medical profession should persist in denying, yea, in heaping obloquy and ridicule upon a science of which they know themselves - and confess themselves - to be wholly or essentially ignorant. ${ }^{, 13}$ He was one of many physicians who initially set out to disprove homeopathy but, after studying the discipline closely, became convinced of its curative powers and ultimately trained as a homeopathic physician.

Particular mention must also be made of Dr Edwin Awdas Neatby, Dr Thomas Miller Neatby, Dr Washington Epps and Dr John Epps. The latter, along with then President, Dr George Burford, and others were instrumental in the establishment of the British Homeopathic Association (BHA) in 1902 , a charity dedicated to promoting and developing the study and practice of homeopathy. Today, the BHA is the leading homeopathy charity in the UK and continues to work closely with and support the activities of the Faculty of Homeopathy.

In 1903, the Missionary School of Medicine was established to provide courses for non-medical missionaries before they left the UK to take the Christian gospel to other parts of the world. In addition to homeopathy, the teaching included some aspects of tropical medicine and surgery, with many of the graduates of the School playing an important role in taking homeopathy to other countries. ${ }^{14}$

Another important transatlantic link was from 1908 to 1913, when the Sir Henry Tyler Scholarship enabled a number of young UK homeopathic doctors to travel to Chicago to train with Dr James T Kent. Amongst them was Sir Henry's daughter, Dr Margaret Tyler, who later became one of the most influential homeopaths of her generation. One of her most famous publications, Tyler's 'Homoeopathic Drug Pictures' continues to be a reference source for practitioners today. Tyler also brought back to the UK the Kentian philosophy, with its high-potency prescribing and increasing emphasis on the 'constitution'. Whilst this clashed with the traditional Hughesian philosophy that had been so prevalent previously, through the influence of Tyler and her colleagues, UK homeopathic practice had changed forever.

Others amongst that group who trained in the USA were Dr (later Sir) John Weir, Dr Douglas Borland, Dr Robert Gibson Miller and Dr Harold Fergie Woods. Sir John Weir became a giant in homeopathy and was homeopathic physician to six different monarchs: King Haakon VII of Norway, King Edward VII, King George V, King Edward VIII, King George VI and Queen Elizabeth II. One of the most enduring traditions throughout the history of homeopathy in the UK has been the appointment of homeopathic physicians to the Royal Family. Dr Quin was the first such appointment and this practice has continued in the years since then, with various Faculty members providing medical services personally to the reigning Monarch and their family. In addition to Sir John Weir, Dr Margery Blackie, Dr Charles Elliott, Dr R William Davey and Dr Peter Fisher have all had responsibilities in this regard.

\section{Carrying the Torch, 1944-2019}

As World War II was drawing to a close and in the years that followed, there were radical changes in how healthcare was delivered in the UK. A 1944 'White Paper' paved the way for 
the NHS Act 1946, which later came into effect in 1948 , establishing a new and comprehensive 'National Health Service' for all citizens, free at the point of delivery. This was a significant development and completely changed the way in which healthcare was delivered across the UK. Agreements were reached that resulted in the existing homeopathic hospitals becoming part of the NHS. In the discussions leading up to this change, it was felt by many that the future of homeopathy would be better served if the BHS were to change its name to 'The Faculty of Homeopathy' and pursue a structure similar to other Royal Colleges. This was agreed in 1943 , with the change taking place in 1944 , on the centenary of the establishment of the organisation.

The first President to take the Chair of the newly named organisation (and the 52nd President since the original founding in 1844) was Sir John Weir. In a speech, recounting a previous meeting with Dr W E Boyd and Dr John Paterson, he acknowledged '...the heritage we had received from the keen observers of the past, but urged us at all costs to preserve that heritage, enlarge and develop it for the future generation of medical men'. ${ }^{15}$ In addition, he appealed '...for help to make the Journal a valuable agent in disseminating the knowledge of Homeopathy'. These words are just as applicable in 2019 as they were back then.

Sir John went on to say, 'I would like to appeal to you all for loyalty to the Faculty and all that it stands for. It means much to the President and Council of any Society to have the sympathetic interest and co-operation of its members, and the presence of a full gathering is stimulating not only to the individual but to others. Regular attendance at a medical society should be a duty. Roosevelt has said that every man owes part of his time to the upbuilding of the profession to which he belongs. From the earliest times men have felt the need of some common medium to draw them together, hence organized societies, and the greatest service rendered was usually to the members themselves. It should be the intention of every member to take some active part in the business of the organization, and it brings out the best that is in him. ${ }^{15}$

He concluded with: 'Does the medical world belong only to the generation which inhabits it? Is it not rather an entailed estate, the income of which the present possessors have the right to enjoy, but not the right to squander or scatter? Are they not in honour bound to preserve the estate intact, institute and develop such permanent improvements as will tend to meet the wants of the generations which will follow? ${ }^{15}$ I trust that these words will be a challenge to all readers, contributors and editors of this journal, and to all of us who are associated with the discipline of homeopathy.

One of Sir John Weir's brightest and most outstanding students was Dr Margery Blackie, who also left deep impressions not only on the homeopathy world but on all who came into contact with her. Her uncle was Dr James Compton Burnett and, even as a child, she always wanted to be a doctor. In addition to occupying various roles in the Faculty of Homeopathy, she was appointed the first female President of the organisation in 1949. Allied to her work in her private practice, she was a Consultant at the RLHH and, in 1968, was appointed as homeopathic physician to Her Majesty the Queen. She had a deep interest in the promotion of homeopathy amongst other medical doctors and conducted regular teaching courses and 'fork suppers' in London. I am aware that a number of readers of this journal have fond memories of those days spent learning from Dr Blackie. She was a brilliant teacher with an international reputation. Her often vivid descriptions of various constitutional types left deep impressions on her students and all those who attended her classes. In order to ensure that this educational work could continue in future and also to encourage research within homeopathy, she established the Blackie Foundation Trust in 1971. This remains active today and the Faculty is grateful to the Trustees for their generous support of this journal.

Arising from his experience in the Children's Department of the RLHH, Dr Donald Foubister was the first person to describe the Carcinosin drug picture, publishing a landmark paper in $1958,{ }^{16}$ followed by a second paper in $1967 .{ }^{17}$ His clinical experience correlated with the provings that had been undertaken by his colleague, Dr William Lees Templeton. Mention must also be made of the work of Drs Charles Wheeler, John Paterson and Elizabeth Paterson: between them they published extensive papers in this journal and brought to us the unique remedies that we have come to know as the 'bowel nosodes."18-21

In 1950, the Faculty was incorporated by an Act of the UK Parliament, the Faculty of Homeopathy Act 1950. The Act recognises the Faculty's role in regulating the education, training and practice of homeopathy by the medical profession. Amendments to the Byelaws and Regulations over the years have extended the Faculty's role to include other statutorily registered healthcare professionals. As Dr Blackie commented, 'This puts us in a unique position. The Colleges of Physicians, Surgeons and Gynaecologists have a Royal Charter, but no other medical body is incorporated by Act of Parliament. $^{22}$

One of the lowest points in the history of the Faculty of Homeopathy and the wider homeopathic community was on 18th June 1972 when a group of 16 homeopathic doctors and colleagues were on board Flight BE548 en route to the Congress of the International Homoeopathic League in Brussels. Within only 3 minutes of taking off from London Heathrow Airport, the Trident jet crashed near the town of Staines, killing all 118 people on board. The accident became known as the Staines Air Disaster and remains one of the worst air catastrophes in the United Kingdom.

Amongst the dead were some of the brightest lights of the homeopathic community, including Dr John Raeside, one of the senior doctors at the RLHH and assistant to Dr Margery Blackie. Dudley Wootton Everitt, head of Nelson's Pharmacy, also died along with his wife, Margot Everitt, as did the young Dr Sergei William Kadleigh, another of Dr Blackie's assistants. As at other times during our history, the event was documented in the journal, ${ }^{23}$ with the obituaries of those who died appearing in the subsequent edition. $^{24}$ The effects of the loss of these 16 senior colleagues was enormous and the impact was felt for many years afterwards. 
In the years since then, the following colleagues have occupied the post of President of the Faculty of Homeopathy: Dr Charles Oliver Kennedy, Dr Geoffrey Martin, Dr Hamish Boyd, Dr Barry Rose, Dr John Hughes-Games, Dr David Spence, Dr Amitav Ghosh, Dr David Ratsey, The Right Hon Dr Dickson Mabon, Dr David Owen and Dr Bob Leckridge. In 2005, in keeping with the increasingly multi-disciplinary nature of the organisation, Mr John Saxton became the first veterinary surgeon to be elected President. In 2008, Dr Sara Eames became only the second female to be elected President, followed by $\mathrm{Dr}$ Helen Beaumont in 2014. In 2018, the organisation was privileged to have Dr Peter Fisher as President for 5 short months before his untimely death on 15th August 2018. Although Dr Fisher had occupied many other roles within the organisation in the past-not least his long-term role as Editor-in-Chief of the journal-this was the first time that he had held the position of President. Upon his death, I became Acting President, prior to my formal election at the Faculty's Annual General Meeting in 2019.

Space does not permit me to include the names of many other influential and popular colleagues who have graced the stage of the Faculty of Homeopathy over the years. Drs William Bayes, Edward Bach, Thomas Dishington, James Kenyon, Douglas Borland and Ralph Twentyman are amongst many who made outstanding contributions to homeopathy.

My mind is drawn also to the various other professions that constitute the Faculty, and I am reminded of those giants of pharmacy, John Ainsworth and Steven Kayne, whose work was crucial to the continued availability of homeopathic medicines and to the training of many homeopathic pharmacists. Likewise, veterinarians George Macleod and Chris Day were instrumental in the establishment of veterinary homeopathy and their legacy is evident to all within the Faculty and the wider veterinary profession.

\section{Enthusiasm in the Present}

From small beginnings, the Faculty has grown to become a large international organisation, with members in many countries worldwide. The Faculty has long been recognised as the pre-eminent membership organisation for statutorily regulated healthcare professionals who integrate homeopathy within their practice. Alongside increasing internationalism, the Faculty has also become increasingly multidisciplinary, embracing a wide range of healthcare professionals. Recent changes to its membership eligibility criteria have increased its appeal further to a wider cohort of practitioners.

In addition to membership activities, the Faculty has an important academic role in terms of setting educational standards for clinicians' professional training in homeopathy. The Faculty provides internationally recognised training pathways in homeopathy for doctors, dentists, pharmacists, vets and other statutorily regulated healthcare professionals. The Faculty's qualifications were among the first available anywhere in the world for medical doctors who practice homeopathy. Today these qualifications remain highly sought after and recognised around the world. A further aspect of Faculty work is, of course, in relation to researchand specifically this journal, which is produced in partnership with Thieme Medical Publishers.

The Faculty also has a robust system of quality assurance that is well placed to develop further in future years. One aspect is the Faculty's status as a General Medical Council (GMC) 'Designated Body', offering annual appraisals to doctors and recommendations about the revalidation of doctors every 5 years to the GMC.

Promotion is another important activity of the Faculty, which actively promotes homeopathy within public, professional, political and scientific circles alike, defending the discipline and maintaining awareness of this effective and safe system of medicine. Given that most Faculty members have dual qualification and training in both conventional and homeopathic medicine, they have a unique perspective on healthcare and can effectively integrate these approaches.

All of these various activities are summarised in the Faculty's recently updated mission statement, which reads simply, 'To promote and support the highest standards of practice, education and research in Homeopathy'.

The Faculty's increasing international stance was illustrated this year by new collaborations with various different countries, which I look forward to see strengthening and increasing in the future. In April 2019, a Scientific Convention was arranged in Delhi, jointly organised by the Faculty of Homeopathy and India's Central Council for Research in Homeopathy. At that meeting, I was reminded afresh of many of the historical links between India and the UK and many of the eminent Indian homeopaths who have been associated with the Faculty of Homeopathy over the years. Herein is another separate article waiting to be written, but at present I am mindful of Dr P. K. Choudary, BSc, MBBS, FFHom, Dr R. S. Pareek, MDH, DFHom, Dr A. U. Ramakrishnan MBBS MFHom, PhD, Dr P. Sankaran, DFHom, Dr S. R. Wadia, MBBS, MFHom, and Dr C. C. Desai MBBS, DMS, MFHom. These are all highly respected names who, after having studied and gained qualifications from the Faculty of Homeopathy, went on to play important roles in the success and the respect in which homeopathy is now held in India and elsewhere in the world.

The most recent development in the Faculty's history came in June 2019, when His Royal Highness The Prince of Wales was announced as Patron of the Faculty of Homeopathy. This is an enormous honour not only for the Faculty but also for the entire homeopathy community. It is a fitting celebration of our 175 years and is also a fitting memorial to our late friend, colleague, former Editor-in-Chief and Faculty President, Dr Peter Fisher.

\section{Encouragement for the Future}

With such weight of history behind us, so many examples of excellence, determination and inspiration, I am both encouraged and challenged as I look to the future. Whilst 
those of us in the current generation of homeopathic practitioners have endured considerable opposition and difficulties, in many ways we are more privileged than those in the past, having the great example of our predecessors to follow. However, each of the names mentioned in this editorial has left an indelible impression on and a lasting contribution to the practice of homeopathy. To quote Johann Wolfgang von Goethe, 'The best thing which we derive from history is the enthusiasm that it raises in us'. The challenge is palpable to each of us to do what we can to ensure that we continue to build and expand both homeopathy and the Faculty of Homeopathy. Whilst there are certainly many challenges, there are also a great many opportunities.

When our colleagues in the AIH were building the monument to Samuel Hahnemann in Washington DC, one of the comments that they inscribed on the monument was 'Non Inutilis Vixi'-'I have not lived in vain'. This was certainly true of Hahnemann but could also be said for many others who followed after him. It is our responsibility to continue to carry the torch forward with a similar determination, ensuring that homeopathy thrives in the future and that increasing numbers of patients have access to homeopathic treatment. Furthermore, we must ensure that when another generation in 25 years' time writes about the 200th anniversary of the Faculty of Homeopathy, they will have the same pride in their history as that which we enjoy today.

Despite the richness of our past, I firmly believe that the words of C. S. Lewis are particularly applicable, when he said, 'There are far, far better things ahead than any we leave behind'. It is clear that the scientific evidence base for homeopathy is growing and soon should reach a critical mass that cannot be ignored or refuted. There is abundant evidence that the high dilutions used in homeopathy have positive effects beyond those of placebo. Clinical research is demonstrating that homeopathy is both safe and effective for a range of conditions. Despite some harsh opposition, homeopathy is increasing in popularity in many countries and there is clear evidence that integrating homeopathy within healthcare systems is associated with improved outcomes, less use of drugs including antibiotics, and economic benefits. Such is the weight of evidence that is now available, a leading Swedish researcher has remarked: 'To conclude that homeopathy lacks clinical effect, more than $90 \%$ of the available clinical trials had to be disregarded. Alternatively, flawed statistical methods had to be applied. $^{25}$

As we look forward, let us do so with positivity, with pride, with ambition and with determination. Let us embrace creativity, innovation and collaboration, forging new relationships and new international links with like-minded colleagues around the world. At the grand old age of 175 years, we look into the future with optimism.

As I close, I wish to express my heartfelt thanks to all those who have contributed to the success of both the Faculty of Homeopathy and this journal. Whether a member, friend, colleague, collaborator, donor, editor, publisher, researcher, subscriber, teacher or reader-every individual has played an important part in bringing us collectively to this point in time.

I am reminded of Dr Frank Bodman's 1961 paper on 'The Life and Times of Dr Quin'.26 Dr Bodman spoke about the influence and lasting legacy of Dr Quin and drew attention to the inscription at the grave of Sir Christopher Wren in St Paul's Cathedral, London. This reads simply 'Lector Si Monumentum Requiris Circumspice'-that is, 'Reader, if you seek his monument look around you'.

The lasting legacy of all of those colleagues whom I have mentioned is literally all around us. Together they have established homeopathy as a system of medicine, the Faculty of Homeopathy as a respected international organisation, and this journal as a key vehicle for the publication of highquality scientific research in homeopathy. May each of us feel the weight of the past upon our shoulders and carry on this good work into the future. The Faculty of Homeopathy and this journal have both played a significant part in homeopathy's history, and both will continue to contribute importantly to its future development.

Conflict of Interest

None declared.

\section{References}

1 Saltzman S. The brilliance of homeopathic medicine. Homeopathy 2019;108:230-231

2 Morrell P. A history of homoeopathy in Britain. 1998 [Online]. Available at: http://www.homeoint.org/morrell/articles/pm_brita. htm. Accessed September 19, 2019

3 Chou JY. Reforming towards a scientific medicine and a changing social identity: British homoeopathy, 1866-1893. PhD thesis, University College London; London; 2016

4 Young S. Sue Young Histories [Online]. Available at: https://www. sueyounghistories.com. Accessed September 19, 2019

5 Fisher P. 100 years of homeopathy. Homeopathy 2011;100:1-4

6 Campbell A. Reflections on 100 years of the journal. Homeopathy 2011;100:5-8

7 Taylor G, Walker J. Charles Harrison Blackley, 1820-1900. Clin Allergy 1973;3:103-108

8 Blackley C, Beecher HW. Experimental Researches on the Causes and Nature of Catarrhus aestivus (Hay Fever or Hay Asthma). London: Baillière, Tindall \& Cox; 1873

9 Crameri R, ed. Allergy and asthma in modern society: a scientific approach. Chem Immunol Allergy. Basel: Karger; 2006:3-15

10 Hughes R, Dake JP. A Cyclopaedia of Drug Pathogenesy. London: Gould \& Son; New York: Boericke \& Tafel; 1891

11 Haehl R. Samuel Hahnemann: His Life and Work. Volume 1. London: Homoeopathic Publishing Company; 1922:361

12 Cameron H. Introductory address. Journal of the British Homoeopathic Society 1894;II:1-6

13 Cooke NF. Annual Address. Transactions of the Twentieth Session of the American Institute of Homoeopathy 1868;1:100-102

14 Davies AE. The history of MSM-homeopathy and natural medicines. Homeopathy 2007;96:52-59

15 Weir J. Valedictory remarks. Br Homoeopath J 1945;35:80-84

16 Foubister DM. The Carcinosin drug picture. Br Homoeopath J 1958;47:201-212

17 Foubister DM. The Carcinosin drug picture. Br Homoeopath J 1967; 56:180-185

18 Bach E, Wheeler CE. Chronic Disease, a Working Hypothesis. London: H. K. Lewis \& Co Ltd.; 1925 
19 Paterson J. Psora in children and the use of the Bach nosodes. Br Homoeopath J 1929;19:51-60

20 Paterson J. The role of the bowel flora in chronic disease. $\mathrm{Br}$ Homoeopath J 1949;39:3-26

21 Paterson J. The bowel nosodes. Br Homoeopath J 1950;40:153-162

22 Blackie MG. The place of homoeopathy in modern medicine. $\mathrm{Br}$ Homoeopath J 1950;40:15-23
23 Twentyman LR. Memorial address. Br Homoeopath J 1972; 61:130-133

24 Obituaries. Br Homoeopath J 1972;61:247-254

25 Hahn RG. Homeopathy: meta-analyses of pooled clinical data. Forsch Komplement Med 2013;20:376-381

26 Bodman F. The life and times of Dr Quin. Br Homoeopath J 1961; 50:73-82 